\title{
Cervical sagittal alignment in patients with adolescent idiopathic scoliosis: is it corrected by surgery?
}

\author{
Jae Hwan Cho, MD, Chang Ju Hwang, MD, PhD, Young Hyun Choi, MD, Dong-Ho Lee, MD, PhD, \\ and Choon Sung Lee, MD, PhD
}

Department of Orthopedic Surgery, Asan Medical Center, University of Ulsan College of Medicine, Seoul, Korea

OBJECTIVE Cervical sagittal alignment (CSA) is related to function and quality of life, but it has not been frequently studied in patients with adolescent idiopathic scoliosis. This study aimed to reveal the change in CSA following corrective surgery, compare the cervical sagittal parameters according to curve types, and assess related factors for postoperative aggravation of CSA.

METHODS The authors studied 318 consecutive patients with adolescent idiopathic scoliosis who underwent corrective surgery at a single center. Occiput-C2 and C2-7 lordosis, C2-7 sagittal vertical axis (SVA), T-1 slope, thoracic kyphosis, and lumbar sagittal profiles were measured preoperatively and postoperatively. Scoliosis Research Society Outcomes Questionnaire (SRS-22) scores were used as clinical outcomes. Each radiological parameter was compared preoperatively and postoperatively according to curve types (double major, single thoracic, and double thoracic curves). Patients were grouped based on preoperative CSA: the lordotic group (group L) and the kyphotic group (group K). Each radiological parameter was compared between the groups. Related factors for postoperative aggravation of CSA were assessed using multivariate logistic analysis.

RESULTS Of the total number of patients studied, $67.0 \%$ (213 of 318 ) and $54.4 \%$ (173 of 318) showed cervical kyphotic alignment preoperatively and postoperatively, respectively. C2-7 lordosis increased (from $-5.8^{\circ}$ to $-1.1^{\circ} ; p<0.001$ ) and C2-7 SVA decreased (from 24.2 to $20.0 \mathrm{~mm}$; $p<0.001$ ) postoperatively regardless of curve types. Although group $\mathrm{K}$ showed improvement in $\mathrm{C} 2-7$ lordosis (from $-12.7^{\circ}$ to $-4.8^{\circ} ; p<0.001$ ), group $\mathrm{L}$ showed no difference (from $9.0^{\circ}$ to $6.9^{\circ}$; $p=0.115)$ postoperatively. Clinical outcomes were not related to the degree of cervical kyphosis in this cohort. C2-7 lordosis $(p<0.001)$ and pelvic tilt $(p=0.019)$ were related to postoperative aggravation of CSA.

CONCLUSIONS Regardless of the trend of improvement in CSA, many patients (54.4\%) still showed cervical kyphotic alignment postoperatively. C2-7 lordosis and C2-7 SVA improved postoperatively in all curve types. However, postoperative changes in C2-7 lordosis showed different results based on preoperative CSA, which could be related to T-1 slope and thoracic kyphosis. However, clinical outcomes showed no difference based on CSA in this study cohort. Greater C2-7 lordosis and proximal thoracic curve preoperatively were risk factors for postoperative aggravation of CSA ( $p<$ 0.001 and $p=0.019$, respectively).

https://thejns.org/doi/abs/10.3171/2017.8.PEDS17357

KEY WORDS adolescent idiopathic scoliosis; cervical; sagittal alignment; lordosis; kyphosis; spine

A DOLESCENT idiopathic scoliosis (AIS) is a 3D deformity characterized by scoliosis in the coronal plane, vertebral rotation, and change in the sagittal profile. Hypokyphosis has been frequently found in patients with AIS, indicating that loss of cervical lordo- sis might be common because of a compensatory mechanism.11,16 Recently, sagittal imbalance of the spine has received attention because dysfunction and quality of life have been reported to be correlated with it. ${ }^{3,4,12}$ Reportedly, a positive correlation may exist between $\mathrm{C}-7$ sagittal verti-

ABBREVIATIONS AIS = adolescent idiopathic scoliosis; $C S A=$ cervical sagittal alignment; ICC = intraclass correlation coefficient; $L L=$ lumbar lordosis; $M T=$ midthoracic; Oc = occiput; PT = proximal thoracic; SRS = Scoliosis Research Society; SS = sacral slope; SVA = sagittal vertical axis; TK = thoracic kyphosis; TL/L = thoracolumbar/lumbar; UIV = upper instrumented vertebra.

SUBMITTED June 26, 2017. ACCEPTED August 11, 2017.

INCLUDE WHEN CITING Published online December 15, 2017; DOI: 10.3171/2017.8.PEDS17357. 
cal axis (SVA) and pain or functional disability following surgeries for degenerative lumbar spine disease and deformities. ${ }^{4}$ However, global sagittal imbalance is not a common problem following corrective surgery for AIS.

In addition, cervical kyphosis may be related to neck pain and functional disability. ${ }^{19}$ Because cervical sagittal curvature is influenced by thoracic sagittal profiles, it can be an important consideration in corrective surgery for AIS. Most patients with AIS have been reported to show cervical kyphotic curvature. ${ }^{9}$ However, the effect of corrective surgery on cervical sagittal alignment (CSA) is not clearly defined. Cervical lordosis has been reported to decrease following corrective surgery in patients with Lenke type 1 AIS. ${ }^{6}$ In addition, the cervical spine may tend to decompensate independent of the surgical technique. ${ }^{14}$ However, there have been varied opinions on postoperative CSA. Reportedly, the effect of corrective surgery on CSA may be determined based on the preoperative thoracic sagittal profile,,$^{18}$ that is, cervical lordosis improves postoperatively in patients with preoperative hypokyphosis; however, a reverse effect has been observed in patients with preoperative normokyphosis. ${ }^{18}$

In these studies, no definite conclusion has been reached regarding CSA in patients with AIS. Furthermore, to our knowledge, no study has compared the postoperative changes in CSA according to curve types in patients with AIS. Thus, this study aimed to reveal the change in CSA following corrective surgery, compare the preoperative and postoperative cervical sagittal parameters according to curve types, and assess related factors for postoperative aggravation of CSA.

\section{Methods}

We studied 318 consecutive patients with AIS who underwent corrective surgery between January 2010 and December 2012 at our institution. All patients were followed for at least 2 years. Demographic data, including sex, age, height, and weight, were obtained from electronic medical records. Clinical data were assessed using Scoliosis Research Society (SRS) Outcomes Questionnaire (SRS-22) scores. Radiological data were obtained from whole-spine anteroposterior and lateral radiographs using the picture archiving communication system at our institution. Plain radiographs were obtained with patients in a standing position in both views and with their arms folded forward in lateral views.

All patients underwent corrective surgery using rod derotation with pedicle screw fixation. A hybrid method with hooks was not used. Pedicle screws were inserted at all levels. Direct vertebral rotation or thoracoplasty was not performed. All procedures were performed by a single surgeon. Curve types were determined based on Lenke classification as follows: 1) double major curve, 2) single thoracic curve, 3) double thoracic curve, and 4) other curve types. ${ }^{15}$

Patients were divided into 2 groups based on the preoperative status of CSA: the cervical lordosis group (group $\mathrm{L}$ ) and the kyphosis group (group $\mathrm{K}$ ). If preoperative $\mathrm{C} 2-7$ lordosis was $<0^{\circ}$, patients were assigned to group $\mathrm{K}$. Otherwise, patients were assigned to group L. All patients were regularly followed with serial radiographs obtained 1,6 , and 12 months after surgery and yearly thereafter. This study was approved by the institutional review board of our institution, which waived the requirement for informed consent because of the retrospective nature of the data analysis.

\section{Radiological Assessment}

Radiological outcomes included the degree of curves and coronal and sagittal balance. The degree of proximal thoracic (PT), midthoracic (MT), and thoracolumbar/ lumbar (TL/L) curves were assessed using the preoperative and postoperative Cobb angle method. The degree of trunk shift was assessed as the distance between the C-7 plumb line and the central sacral vertical line for wholespine standing anteroposterior radiographs. The T-1 tilt was defined as the angle between the T-1 upper endplate and the horizontal line to the ground in standing radiographs. The sagittal parameters included occiput (Oc)-C2 and C2-7 lordosis, C2-7 SVA, T-1 slope, thoracic kyphosis (TK), lumbar lordosis (LL), sacral slope (SS), and C7S1 SVA.

$\mathrm{Oc}-\mathrm{C} 2$ lordosis was measured as the angle between the line from the anterosuperior border of the atlas to the inferior end of the occiput and lower endplates of C-2. C2-7 lordosis was defined as the Cobb angle between the lower endplates of C-2 and C-7. C2-7 SVA was defined as the distance from the posterosuperior corner of $\mathrm{C}-7$ and the vertical line from the center of the C-2 body. T-1 slope was measured as the angle between the upper endplate of $\mathrm{T}-1$ and the horizontal line to the ground in standing radiographs. TK was measured as the Cobb angle between the upper endplate of T-1 and the lower endplate of T-12. LL was defined as the Cobb angle between both upper endplates of L-1 and S-1. SS was defined as the angle between the upper endplates of the sacrum and the horizontal line to the ground in standing radiographs. The C7-S1 SVA was defined as the distance from the posterosuperior corner of S-1 and the vertical line from the center of the C-7 body.

Each radiological parameter was assessed by 2 independent surgeons, and the assessment was repeated after a 1 -month interval. The mean values of measurements were used for analysis. The methods of measurement are summarized in Fig. 1.

\section{Statistical Analysis}

Demographic data were descriptively analyzed. Radiological parameters were compared between each followup period using a paired t-test. Postoperative changes in radiological parameters were compared among curve types using analysis of variance and the chi-square test. Post hoc analysis was performed using Bonferroni correction. Comparisons between groups $\mathrm{L}$ and $\mathrm{K}$ were performed using an independent t-test. Correlation analysis was performed between preoperative cervical lordosis and postoperative changes in cervical lordosis.

Intra- and interobserver agreements were assessed using the intraclass correlation coefficient (ICC) method. Each domain of SRS-22 scores was compared according 

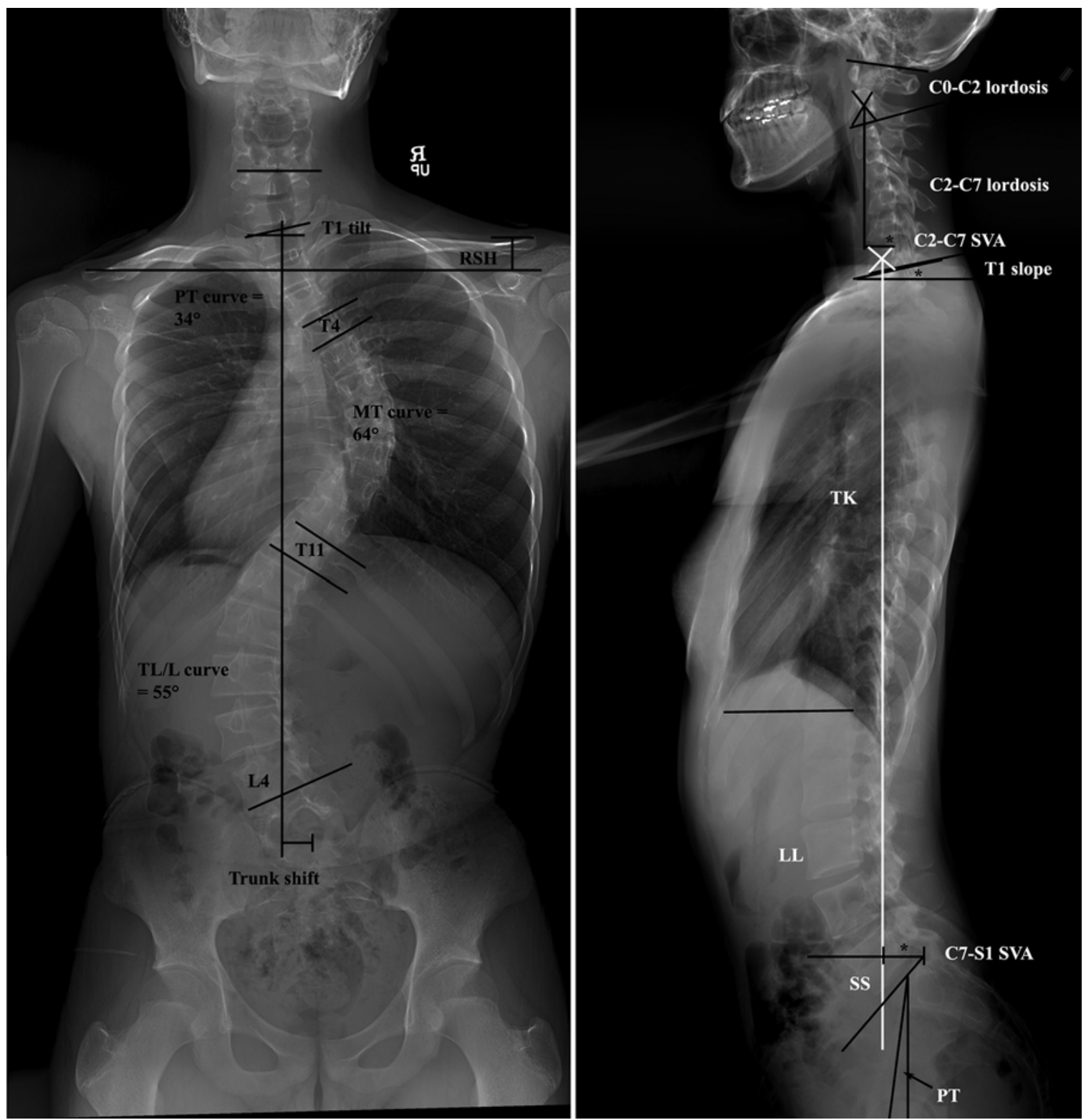

FIG. 1. Measurements of radiological, coronal, and sagittal parameters. RSH = radiological shoulder height.

to CSA using an independent t-test. Risk factor analyses were conducted using univariate analysis, followed by multivariate logistic regression analysis. Statistical analyses were performed using Statistical Package for Social Sciences software (version 21.0; SPSS, Inc.), and p values $<0.05$ were considered statistically significant.

\section{Results}

\section{Demographic Data and Curve Type}

This study included 45 boys and 273 girls with a mean age of $15.5 \pm 4.3$ years, a mean height of $158.8 \pm 8.1 \mathrm{~cm}$, and a mean weight of $49.1 \pm 9.3 \mathrm{~kg}$. The mean follow-up was $38.4 \pm 13.5$ months. The mean fusion level was 11.0 \pm 1.6 .

Curve types were determined as follows: 152 double major (Lenke type 3C and 6C), 82 single thoracic (Lenke type 1), 38 double thoracic (Lenke type 2), and 46 other type curves. The most commonly selected upper instrumented vertebra (UIV) was T-4 (171 of 318, 53.8\%), followed by T-3 ( 77 of $318,24.2 \%)$. The most commonly selected lower instrumented vertebra was L-3 (122 of 318, $38.4 \%$ ), followed by L-1 (93 of 318, 29.2\%). Demographic data according to curve types are summarized in Table 1.

\section{Comparisons of Radiological Parameters According to Curve Type}

Serial radiographs showed immediate restoration of $\mathrm{C} 2-7$ lordosis, and this restoration was maintained throughout the follow-up. However, improvement in C2-7 SVA occurred mainly between 1 and 2 years postoperatively and was maintained thereafter (Table 2). 
TABLE 1. Preoperative demographic data and radiological parameters according to curve type

\begin{tabular}{lcccc}
\hline \multicolumn{1}{c}{ Variable } & $\begin{array}{c}\text { Double Major } \\
(\text { Lenke types 3C, 6C) }\end{array}$ & $\begin{array}{c}\text { Single Thoracic } \\
(\text { Lenke type 1) }\end{array}$ & $\begin{array}{c}\text { Double Thoracic } \\
(\text { Lenke type 2) }\end{array}$ & Total \\
\hline No. of patients & 152 & 82 & 38 & 318 \\
\hline Sex (M/F) & $21: 131$ & $11: 71$ & $8: 30$ & $45: 273$ \\
\hline Age (yrs) & $15.5 \pm 4.3$ & $16.0 \pm 5.3$ & $14.6 \pm 2.1$ & $15.5 \pm 4.3$ \\
\hline Height (cm) & $159.8 \pm 7.9$ & $157.8 \pm 9.1$ & $158.7 \pm 7.8$ & $158.8 \pm 8.1$ \\
\hline Weight (kg) & $50.2 \pm 9.3$ & $48.2 \pm 9.6$ & $48.3 \pm 9.7$ & $49.1 \pm 9.3$ \\
\hline BMl (kg/m²) & $19.6 \pm 2.8$ & $19.3 \pm 3.4$ & $19.0 \pm 2.8$ & $19.4 \pm 2.9$ \\
\hline UIV (no.) & T-3 (23), T-4 (100), T-5 (22), & T-3 (26), T-4 (50), & T-2 (4), T-3 (24), & T-3 (77), T-4 (171), T-5 (32), \\
\hline LIV (no.) & others (7) & T-5 (4), others (2) & T-4 (8), others (2) & others (38) \\
\hline No. of fusion levels ${ }^{*}$ & T-12 (8), L-1 (39), L-2 (9), & T-12 (6), L-1 (42), & L-1 (11), L-2 (16), & T-12 (14), L-1 (93), L-2 (55), others (1) \\
\hline FU (mos) & $11.3 \pm 1.5$ & $10.7 \pm 0.9$ & $11.7 \pm 1.3$ & L-3 (122), L-4 (32), others (2) \\
\hline
\end{tabular}

$\mathrm{BMI}=$ body mass index; $\mathrm{FU}=$ follow-up; LIV = lower instrumented vertebra.

* Data are reported as the mean \pm SD.

A comparison of preoperative and postoperative radiological data according to curve types is presented in Table 3. Oc-C2 lordosis did not change postoperatively in any curve type. However, C2-7 lordosis and C2-7 SVA improved postoperatively regardless of curve types. TK increased postoperatively in double major and double thoracic curves (from $24.1^{\circ}$ to $27.5^{\circ}$ and from $20.5^{\circ}$ to $26.3^{\circ}$, respectively). Regarding lumbar sagittal profiles, postoperative changes showed a slight difference according to curve types. LL increased in double major and double thoracic curves (from $43.5^{\circ}$ to $45.3^{\circ}$ and from $36.8^{\circ}$ to $40.8^{\circ}$, respectively); however, SS decreased only in double major curves (from $37.4^{\circ}$ to $36.1^{\circ}$ ). PT curve increased only in single thoracic curves (from $10.0^{\circ}$ to $11.6^{\circ}$ ). C7-S1 SVA decreased in double major and double thoracic curves.

Degrees of postoperative changes in sagittal parameters revealed no difference among curve types, except for PT curve (Table 4). Post hoc analysis showed that PT curve increased in single thoracic curve but decreased in double thoracic curve $(\mathrm{p}=0.043)$.

Postoperative changes in $\mathrm{C} 2-7$ lordosis did not differ

TABLE 2. Serial follow-up of cervical sagittal parameters

\begin{tabular}{lcccc}
\hline \multicolumn{1}{c}{ Exam } & $\begin{array}{c}\text { C2-7 Lordosis } \\
\left({ }^{\circ}\right)^{*}\end{array}$ & $\begin{array}{c}p \\
\text { Value }\end{array}$ & $\begin{array}{c}\text { C2-7 SVA } \\
(\mathrm{mm})\end{array}$ & $\begin{array}{c}\mathrm{p} \\
\text { Value† }\end{array}$ \\
\hline Preop & $-5.8 \pm 13.2$ & & $24.2 \pm 8.9$ & \\
\hline Postop 1 mo & $-2.9 \pm 11.2$ & 0.005 & $23.5 \pm 7.8$ & 0.557 \\
\hline Postop 6 mos & $-2.5 \pm 11.5$ & 0.583 & $24.4 \pm 10.0$ & 0.878 \\
\hline Postop 1 yr & $-2.5 \pm 12.0$ & 0.914 & $23.3 \pm 8.5$ & 0.458 \\
\hline Postop 2 yrs & $-0.5 \pm 12.1$ & 0.111 & $21.8 \pm 7.5$ & 0.019 \\
\hline Postop 3 yrs & $0.6 \pm 14.7$ & 0.185 & $19.7 \pm 7.8$ & 0.138 \\
\hline Postop 4 yrs & $-0.3 \pm 13.8$ & 0.424 & $20.4 \pm 9.4$ & 0.768 \\
\hline Final visit & $-1.1 \pm 13.6$ & 0.166 & $20.0 \pm 9.4$ & 0.828 \\
\hline
\end{tabular}

Data are reported as the mean \pm SD.

* Negative value indicates that the curve is kyphotic.

$\dagger$ Comparisons between each consecutive visit. according to UIV ( $p=0.200)$. These results were also confirmed in subgroup analysis based on each curve type (double major $\mathrm{p}=0.446$, single thoracic $\mathrm{p}=0.806$, and double thoracic $\mathrm{p}=0.165$ ).

\section{Sagittal Parameters According to Preoperative CSA}

Of the total number of patients, $67.0 \%$ (213 of 318) and $54.4 \%$ (173 of 318) showed preoperative and postoperative cervical kyphotic alignment (Fig. 2). Average C2-7 lordosis was $9.0^{\circ}$ in group L and $-12.7^{\circ}$ (kyphotic) in group $\mathrm{K}$. Although $\mathrm{C} 2-7$ lordosis increased in group $\mathrm{K}$ (from $-12.7^{\circ}$ to $\left.-4.8^{\circ} ; \mathrm{p}<0.001\right)$, it did not change postoperatively in group L (from $9.0^{\circ}$ to $6.9^{\circ} ; \mathrm{p}=0.115$ ) (Fig. 3). In addition, T-1 slope increased postoperatively in group $\mathrm{K}$ (from $10.7^{\circ}$ to $12.3^{\circ} ; \mathrm{p}=0.004$ ); however, it decreased in group L (from $19.1^{\circ}$ to $18.4^{\circ} ; \mathrm{p}=0.400$ ). TK increased in both groups. Each sagittal parameter according to preoperative CSA is summarized in Table 5. Only the postoperative changes in C2-7 lordosis showed differences between groups $\mathrm{L}$ and $\mathrm{K}$ in all 3 curve types (Table 6).

Preoperative $\mathrm{C} 2-7$ lordosis was negatively correlated with postoperative changes in $\mathrm{C} 2-7$ lordosis. Pearson correlation coefficients were $-0.488,-0.475$, and -0.377 in double major, single thoracic, and double thoracic curves, respectively. Scatter plots are shown in Fig. 4.

\section{Clinical Outcomes According to CSA}

No domain of SRS-22 scores showed any difference according to CSA (lordosis vs kyphosis) preoperatively and postoperatively (Table 7).

\section{Risk Factors for Aggravation of CSA}

Univariate analyses revealed that $\mathrm{C} 2-7$ cervical lordosis $(\mathrm{p}<0.001), \mathrm{T}-1$ slope $(\mathrm{p}=0.001), \mathrm{TK}(\mathrm{p}=0.031), \mathrm{SS}(\mathrm{p}$ $=0.039)$, and PT curve $(\mathrm{p}=0.012)$ were related to progression of cervical kyphosis postoperatively. However, multivariate logistic regression analysis revealed that only preoperative C2-7 cervical lordosis and PT curve were risk 
TABLE 3. Comparisons of pre- and postoperative radiological parameters according to curve type

\begin{tabular}{|c|c|c|c|c|c|c|c|c|c|}
\hline \multirow{2}{*}{$\begin{array}{l}\text { Radiological } \\
\text { Parameter }\end{array}$} & \multicolumn{3}{|c|}{ Double Major (Lenke types 3C \& 6C) } & \multicolumn{3}{|c|}{ Single Thoracic (Lenke type 1) } & \multicolumn{3}{|c|}{ Double Thoracic (Lenke type 2) } \\
\hline & Preop & Final Visit & $p$ Value & Preop & Final Visit & $p$ Value & Preop & Final Visit & p Value \\
\hline PT curve $\left({ }^{\circ}\right)$ & $22.0 \pm 8.7$ & $8.4 \pm 6.2$ & $<0.001$ & $27.5 \pm 7.3$ & $10.2 \pm 5.1$ & $<0.001$ & $42.0 \pm 12.8$ & $19.9 \pm 6.3$ & $<0.001$ \\
\hline MT curve $\left({ }^{\circ}\right)$ & $50.8 \pm 12.0$ & $12.8 \pm 7.0$ & $<0.001$ & $52.0 \pm 10.2$ & $9.6 \pm 5.0$ & $<0.001$ & $57.3 \pm 13.2$ & $11.4 \pm 6.1$ & $<0.001$ \\
\hline TL/L curve $\left({ }^{\circ}\right)$ & $44.1 \pm 12.0$ & $14.1 \pm 7.9$ & $<0.001$ & $27.4 \pm 7.5$ & $6.3 \pm 5.7$ & $<0.001$ & $26.0 \pm 9.4$ & $4.3 \pm 4.0$ & $<0.001$ \\
\hline Trunk shift $(\mathrm{mm})^{*}$ & $-6.9 \pm 13.2$ & $-6.6 \pm 10.6$ & 0.796 & $6.0 \pm 12.6$ & $-3.8 \pm 9.9$ & $<0.001$ & $3.5 \pm 13.7$ & $-7.1 \pm 10.2$ & $<0.001$ \\
\hline $\mathrm{RSH}(\mathrm{mm}) \dagger$ & $-14.1 \pm 12.4$ & $4.5 \pm 10.4$ & $<0.001$ & $-17.2 \pm 12.8$ & $5.7 \pm 10.7$ & $<0.001$ & $-3.4 \pm 10.5$ & $10.0 \pm 11.6$ & $<0.001$ \\
\hline T-1 tilt $\left({ }^{\circ}\right) \dagger$ & $-3.0 \pm 7.1$ & $2.5 \pm 5.7$ & $<0.001$ & $-3.4 \pm 6.6$ & $4.8 \pm 4.7$ & $<0.001$ & $9.2 \pm 7.3$ & $11.2 \pm 5.3$ & 0.043 \\
\hline $\mathrm{C} 0-2 \mathrm{CL}\left({ }^{\circ}\right)$ & $27.3 \pm 8.7$ & $27.7 \pm 8.5$ & 0.456 & $26.5 \pm 8.8$ & $27.7 \pm 7.9$ & 0.174 & $27.9 \pm 7.5$ & $30.1 \pm 9.2$ & 0.091 \\
\hline $\mathrm{C} 2-7 \mathrm{CL}\left({ }^{\circ}\right) \ddagger$ & $-5.6 \pm 12.8$ & $-0.4 \pm 13.1$ & $<0.001$ & $-7.6 \pm 13.3$ & $-3.2 \pm 13.6$ & 0.004 & $-4.6 \pm 16.5$ & $-1.2 \pm 16.5$ & 0.097 \\
\hline C2-7 SVA (mm) & $24.4 \pm 9.3$ & $20.2 \pm 8.8$ & $<0.001$ & $24.5 \pm 8.7$ & $20.6 \pm 9.5$ & $<0.001$ & $23.4 \pm 7.9$ & $20.0 \pm 10.0$ & 0.013 \\
\hline T-1 slope $\left(^{\circ}\right)$ & $13.4 \pm 8.3$ & $14.3 \pm 8.8$ & 0.223 & $11.7 \pm 8.3$ & $12.6 \pm 9.1$ & 0.312 & $13.4 \pm 10.9$ & $15.8 \pm 11.9$ & 0.049 \\
\hline $\operatorname{TK}\left({ }^{\circ}\right)$ & $24.1 \pm 11.6$ & $27.5 \pm 10.3$ & $<0.001$ & $23.3 \pm 12.7$ & $24.9 \pm 11.3$ & 0.191 & $20.5 \pm 13.5$ & $26.3 \pm 14.3$ & $<0.001$ \\
\hline $\operatorname{LL}\left({ }^{\circ}\right)$ & $43.5 \pm 10.8$ & $45.3 \pm 10.5$ & 0.024 & $44.8 \pm 11.5$ & $44.7 \pm 10.3$ & 0.927 & $36.8 \pm 14.9$ & $40.8 \pm 13.4$ & 0.044 \\
\hline $\operatorname{SS}\left({ }^{\circ}\right)$ & $37.4 \pm 9.1$ & $36.1 \pm 7.7$ & 0.014 & $36.8 \pm 10.6$ & $36.1 \pm 10.0$ & 0.401 & $35.9 \pm 9.6$ & $36.4 \pm 9.6$ & 0.679 \\
\hline Pelvic tilt $\left(^{\circ}\right)$ & $10.5 \pm 7.7$ & $11.4 \pm 7.5$ & 0.078 & $10.0 \pm 5.9$ & $11.6 \pm 6.9$ & 0.006 & $12.3 \pm 8.9$ & $11.1 \pm 6.5$ & 0.251 \\
\hline C7-S1 SVA (mm) & $0.4 \pm 25.2$ & $-6.5 \pm 27.3$ & 0.008 & $-1.6 \pm 28.5$ & $-8.0 \pm 29.9$ & 0.129 & $14.3 \pm 30.4$ & $-5.6 \pm 27.6$ & $<0.001$ \\
\hline
\end{tabular}

$\mathrm{CL}=$ cervical lordosis; $\mathrm{RSH}=$ radiological shoulder height.

Data are reported as the mean \pm SD.

* Negative value indicates that the C-7 plumb line is located on the left side of center of sacrum.

$\dagger$ Negative value indicates that the left side is more depressed than the right side.

$\ddagger$ Negative value indicates that the curve is kyphotic.

factors for aggravation of CSA $(\mathrm{p}<0.001$ and $\mathrm{p}=0.019$, respectively) (Table 8).

\section{Reliability Assessment of Measurements}

Inter- and intraobserver reliability to assess sagittal parameters are summarized in Table 9. Most parameters showed excellent interobserver and intraobserver reliability (ICC > 0.8).

\section{Discussion}

CSA and global sagittal balance in patients with AIS have recently received attention. Our study showed that cervical lordosis improved in patients with preoperative cervical kyphosis; however, it did not change in patients with preoperative cervical lordosis. Several studies have evaluated postoperative changes in CSA. It has been proposed that changes in the cervical sagittal profile vary according to the preoperative sagittal profile of TK. ${ }^{5,18}$ The result was confirmed by our study, which showed larger $\mathrm{T}-1$ slope and TK in group L preoperatively and postoperatively.

Reportedly, TK influences C2-7 lordosis through the T-1 slope,$^{13}$ and $\mathrm{T}-1$ slope can be an important parameter to correlate cervical and thoracic sagittal alignment in AIS. ${ }^{17}$ Interestingly, T-1 slope increased in group K ( $\mathrm{p}=$ $0.004)$, but it did not change in group $L(p=0.400)$, which correlated with no change in cervical lordosis in group

TABLE 4. Comparisons of postoperative changes in sagittal alignment among curve types

\begin{tabular}{|c|c|c|c|c|}
\hline Variable & Double Major (Lenke types 3C \& 6C) & Single Thoracic (Lenke type 1) & Double Thoracic (Lenke type 2) & $\mathrm{p}$ Value \\
\hline Ch_C0-2 CL $\left(^{\circ}\right)$ & $0.4 \pm 7.0$ & $1.3 \pm 8.1$ & $2.2 \pm 7.8$ & 0.388 \\
\hline Ch_C2-7 CL $\left(^{\circ}\right)$ & $5.2 \pm 13.1$ & $4.4 \pm 13.3$ & $3.5 \pm 12.5$ & 0.720 \\
\hline Ch_C2-7 SVA (mm) & $-4.2 \pm 8.1$ & $-3.9 \pm 8.9$ & $-3.4 \pm 8.0$ & 0.851 \\
\hline Ch_T-1 slope $\left({ }^{\circ}\right)$ & $0.9 \pm 8.7$ & $0.9 \pm 7.7$ & $2.5 \pm 7.4$ & 0.547 \\
\hline Ch_TK $\left(^{\circ}\right)$ & $3.5 \pm 10.2$ & $1.6 \pm 10.7$ & $5.9 \pm 7.2$ & 0.088 \\
\hline Ch_LL $\left(^{\circ}\right)$ & $1.8 \pm 9.5$ & $-0.1 \pm 11.1$ & $4.0 \pm 11.9$ & 0.119 \\
\hline Ch_SS $\left(^{\circ}\right)$ & $-1.4 \pm 6.9$ & $-0.8 \pm 8.0$ & $0.5 \pm 7.4$ & 0.350 \\
\hline Ch_pelvic tilt $\left({ }^{\circ}\right)$ & $0.8 \pm 5.8$ & $1.6 \pm 4.9$ & $-1.2 \pm 6.1$ & $0.049^{*}$ \\
\hline Ch_C7-S1 SVA (mm) & $-6.9 \pm 31.8$ & $-6.4 \pm 37.2$ & $-19.8 \pm 33.5$ & 0.088 \\
\hline
\end{tabular}

$\mathrm{Ch}_{-}=$changes of variables between preoperative period and final follow-up.

Data are reported as the mean \pm SD.

* Post hoc analysis revealed that there was a difference between Lenke types 1 and $2(p=0.043)$. 

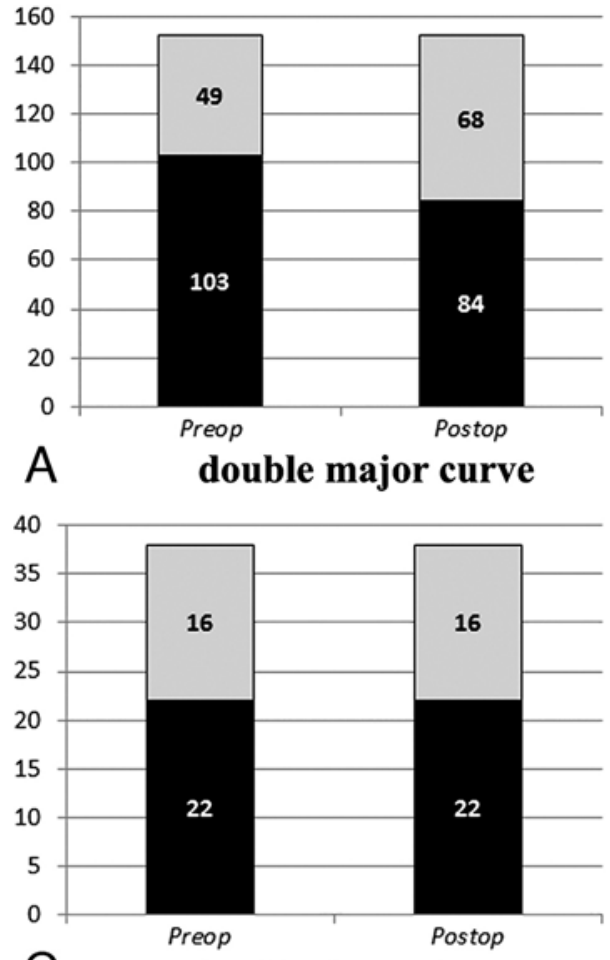

double thoracic curve

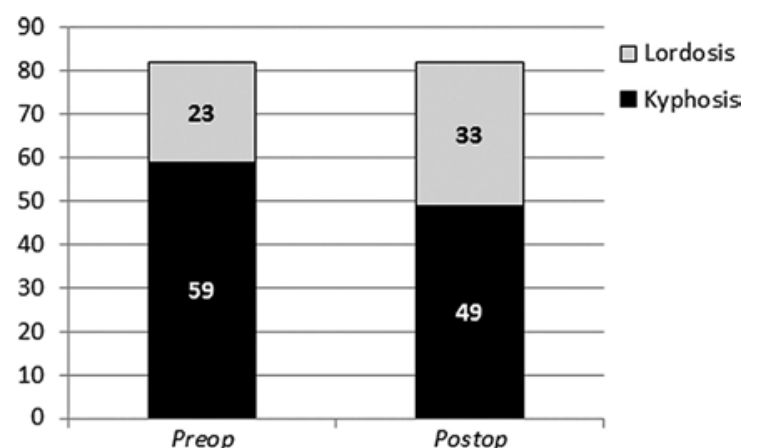

single thoracic curve

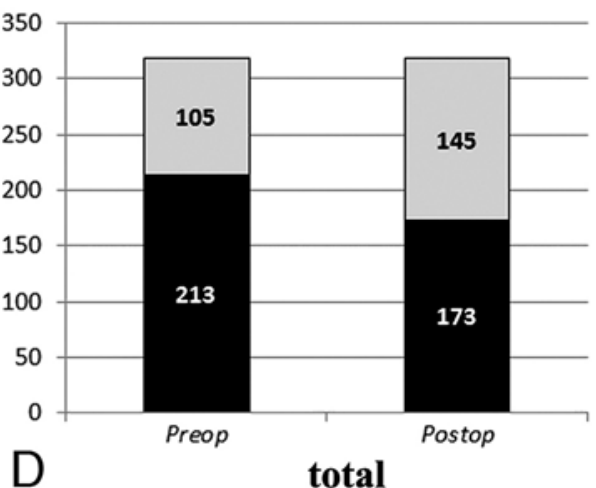

FIG. 2. Distribution of CSA in the preoperative and postoperative periods. A: Double major curve. B: Single thoracic curve. C: Double thoracic curve. D: Total.

$\mathrm{L}(\mathrm{p}=0.115)$ in our study. This indicates that a different compensatory mechanism existed between the 2 groups. It has also been suggested that T-1 slope and C2-7 SVA are related to health-related quality of life in patients with AIS. ${ }^{23}$ However, we found no difference in C2-7 SVA according to preoperative CSA.

Reportedly, C2-7 lordosis is related to the global thoracic sagittal alignment in Lenke type $5 \mathrm{C}$ curves. ${ }^{20}$ In another study, cervical lordosis decreased slightly in Lenke type 3C and 6C curves. ${ }^{22}$ However, to our knowledge, no studies have compared CSA by different curve types. Based on the results of our study, C2-7 lordosis increased in 3 types of curves, although it did not reach statisti-

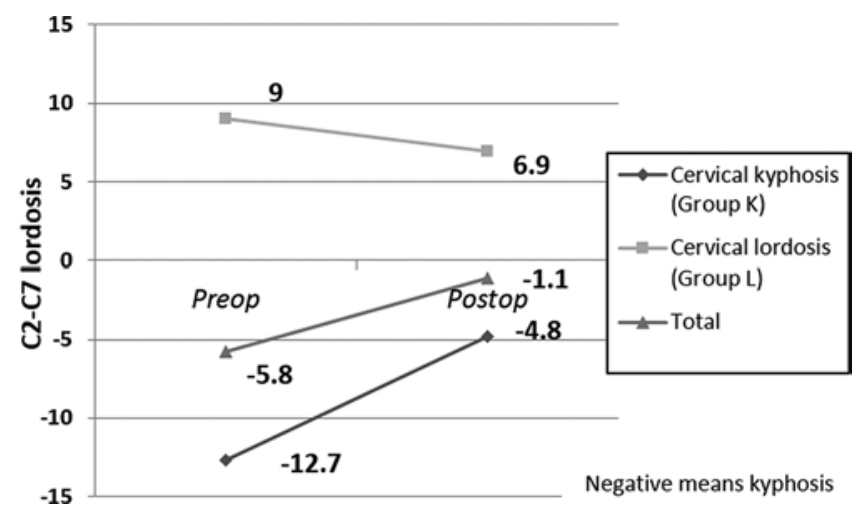

FIG. 3. Postoperative changes in C2-7 lordosis in groups L (preoperative lordotic group) and $\mathrm{K}$ (preoperative kyphotic group). cal significance in double thoracic curves $(p=0.097)$. In double major curves, TK increased without the change in T-1 slope postoperatively. In double thoracic curves, both T-1 slope and TK increased postoperatively, which might be the result of instrumentation to a more upper thoracic level. This could lead to restoration of cervical lordosis.

However, the degree of increasing TK was minimal in the single thoracic curve (from $23.3^{\circ}$ to $24.9^{\circ} ; \mathrm{p}=0.191$ ), which led to only slight change in T-1 slope (from $11.7^{\circ}$ to $12.6^{\circ} ; \mathrm{p}=0.312$ ). This result was different in a recently published study by Hiyama et al., ${ }^{6}$ which showed that reduction in cervical lordosis after operation is affected by the loss of TK in Lenke type 1 curves. The hypokyphotic effect of posterior corrective surgery for Lenke type 1 and 2 curves was also suggested.? However, we could not explain the effect of scoliosis types on CSA based on the above findings.

The relationship between cervical kyphotic change and UIV has been controversial. Reportedly, kyphotic changes in C2-7 sagittal alignment were correlated with the level of UIV in Lenke type 1 curves. ${ }^{14}$ In contrast, it was suggested that postoperative CSA is independent of UIV in Lenke type $3 \mathrm{C}$ and $6 \mathrm{C}$ curves. ${ }^{22}$ Our study also demonstrated that CSA was unrelated to UIV, regardless of curve types. However, our results cannot be compared directly to those of previous studies because patients who underwent correction by hybrid constructs were included in those studies. ${ }^{14}$ In contrast, we used only pedicle screws.

Inherent loss of cervical lordosis in patients with AIS has been suggested by several investigators. ${ }^{9}$ Reportedly, cervical hypolordosis improves with use of the postero- 
TABLE 5. Pre- and postoperative sagittal parameters according to preoperative CSA

\begin{tabular}{|c|c|c|c|c|c|c|}
\hline \multirow[b]{2}{*}{ Sagittal Parameter } & \multicolumn{3}{|c|}{ Group L $(n=105)$} & \multicolumn{3}{|c|}{ Group K $(n=213)$} \\
\hline & Preop & Final Visit & p Value & Preop & Final Visit & $p$ Value \\
\hline $\mathrm{C} 0-2 \mathrm{CL}\left({ }^{\circ}\right)$ & $24.4 \pm 8.7$ & $26.1 \pm 8.4$ & 0.015 & $28.5 \pm 8.2$ & $29.0 \pm 8.5$ & 0.421 \\
\hline $\mathrm{C} 2-7 \mathrm{CL}\left({ }^{\circ}\right)^{*}$ & $9.0 \pm 8.1$ & $6.9 \pm 13.4$ & 0.115 & $-12.7 \pm 8.7$ & $-4.8 \pm 12.1$ & $<0.001$ \\
\hline C2-7 SVA (mm) & $23.7 \pm 9.0$ & $20.2 \pm 8.9$ & $<0.001$ & $24.5 \pm 8.9$ & $19.9 \pm 9.6$ & $<0.001$ \\
\hline T-1 slope $\left({ }^{\circ}\right)$ & $19.1 \pm 8.1$ & $18.4 \pm 9.6$ & 0.400 & $10.7 \pm 7.5$ & $12.3 \pm 8.2$ & 0.004 \\
\hline $\operatorname{TK}\left({ }^{\circ}\right)$ & $30.1 \pm 11.5$ & $32.8 \pm 11.8$ & 0.007 & $20.9 \pm 11.0$ & $24.6 \pm 10.0$ & $<0.001$ \\
\hline $\operatorname{LL}\left({ }^{\circ}\right)$ & $42.5 \pm 12.2$ & $44.8 \pm 10.6$ & 0.022 & $43.1 \pm 11.7$ & $44.8 \pm 11.0$ & 0.021 \\
\hline $\operatorname{SS}\left({ }^{\circ}\right)$ & $34.7 \pm 11.3$ & $34.6 \pm 10.4$ & 0.863 & $37.6 \pm 9.5$ & $36.2 \pm 7.9$ & 0.010 \\
\hline Pelvic tilt $\left({ }^{\circ}\right)$ & $11.2 \pm 8.6$ & $11.5 \pm 7.2$ & 0.635 & $10.5 \pm 6.7$ & $11.1 \pm 7.1$ & 0.113 \\
\hline C7-S1 SVA (mm) & $5.3 \pm 24.1$ & $-7.3 \pm 28.4$ & $<0.001$ & $0.0 \pm 28.5$ & $-7.7 \pm 28.0$ & 0.002 \\
\hline
\end{tabular}

Data are reported as the mean $\pm S D$.

* Negative value indicates that the curve is kyphotic.

medial translation technique, although the proportion of patients who maintain physiological cervical lordosis remains low. ${ }^{8}$ It has been suggested that inherent rigidity of the cervical spine limits changes in CSA. ${ }^{1}$ In our study, the incidence of cervical kyphosis in AIS was as high as $67.0 \%$, and the proportion was still high at $54.4 \%$ postoperatively.

Regardless of the high incidence of cervical kyphosis, the numbers of patients who complained of neck pain are not likely to be higher than expected. In fact, no correlation was found between SRS-22 scores and CSA in our study cohort. However, a correlation between neck pain and cervical sagittal malalignment has been recently proposed ${ }^{21}$ In addition, it could be a problem in the future, even if it is not observed currently.

Although cervical sagittal imbalance existed, global sagittal balance, as measured by C7-S1 SVA, was relatively well maintained in all curve types in our study. It has been suggested that the global spine is well balanced with spontaneous adjustment despite cervical sagittal imbalance. ${ }^{24}$ In contrast, one study proposed that LL may influence cervical lordosis. ${ }^{2}$ It was thought that thoracic sagittal profiles, T-1 slope, and C2-7 lordosis correlated and varied together. However, the effect of correction on lumbar sagittal profiles has not been clearly defined.

In general, it is known that CSA does not directly relate to lumbar sagittal profiles. ${ }^{13}$ However, LL increased postoperatively in double major and double thoracic curves, which might be related to more distal instrumentation. Interestingly, PT curve also increased in double major and single thoracic curves but not in double thoracic curves. In addition, greater PT curve is related to postoperative aggravation of cervical lordosis. La Maida et al. ${ }^{10}$ have proposed that this is a compensatory mechanism. However, further study will be required to reveal the relationship between CSA and PT curve.

This study had a few limitations. First, clinical significance was not considered. Although cervical sagittal malalignment is generally known to be related to pain and dysfunction, it is questionable whether patients with AIS feel neck pain more frequently than normal control subjects. Although SRS-22 score was used for analysis, it was not specified for neck pain or disability. Second, only coronal curve types were considered. It has been proposed

TABLE 6. Comparisons of postoperative changes of radiological parameters according to preoperative CSA in each curve type

\begin{tabular}{|c|c|c|c|c|c|c|c|c|c|}
\hline \multirow[b]{2}{*}{$\begin{array}{l}\text { Radiological } \\
\text { Parameter }\end{array}$} & \multicolumn{3}{|c|}{ Double Major (Lenke types 3C \& 6C) } & \multicolumn{3}{|c|}{ Single Thoracic (Lenke type 1) } & \multicolumn{3}{|c|}{ Double Thoracic (Lenke type 2) } \\
\hline & $\begin{array}{l}\text { Group L } \\
(n=49)\end{array}$ & $\begin{array}{l}\text { Group K } \\
(n=103)\end{array}$ & $\begin{array}{c}p \\
\text { Value }\end{array}$ & $\begin{array}{l}\text { Group L } \\
(n=23)\end{array}$ & $\begin{array}{c}\text { Group K } \\
(n=59)\end{array}$ & $\begin{array}{c}p \\
\text { Value }\end{array}$ & $\begin{array}{l}\text { Group L } \\
(n=16)\end{array}$ & $\begin{array}{l}\text { Group K } \\
(n=22)\end{array}$ & $\begin{array}{c}p \\
\text { Value }\end{array}$ \\
\hline Ch_CO-2 CL $\left(^{\circ}\right)$ & $1.9 \pm 6.7$ & $-0.3 \pm 7.1$ & 0.154 & $2.9 \pm 6.6$ & $0.7 \pm 8.6$ & 0.297 & $0.5 \pm 9.0$ & $3.4 \pm 6.7$ & 0.259 \\
\hline Ch_C2-7 CL $\left(^{\circ}\right)$ & $-1.9 \pm 13.1$ & $8.7 \pm 11.7$ & $<0.001$ & $-4.2 \pm 11.6$ & $7.3 \pm 12.7$ & 0.001 & $-2.6 \pm 14.3$ & $7.8 \pm 9.0$ & 0.009 \\
\hline Ch_C2-7 SVA (mm) & $-3.9 \pm 7.9$ & $-4.2 \pm 8.8$ & 0.278 & $-1.7 \pm 6.2$ & $-4.7 \pm 9.5$ & 0.200 & $-3.0 \pm 6.6$ & $-3.8 \pm 9.1$ & 0.771 \\
\hline Ch_T-1 slope $\left({ }^{\circ}\right)$ & $-0.7 \pm 8.0$ & $1.7 \pm 8.3$ & 0.020 & $1.3 \pm 6.7$ & $0.8 \pm 8.1$ & 0.807 & $0.5 \pm 7.6$ & $3.9 \pm 7.1$ & 0.169 \\
\hline Ch_TK $\left(^{\circ}\right)$ & $2.8 \pm 10.0$ & $3.7 \pm 10.3$ & 0.440 & $1.4 \pm 10.1$ & $1.7 \pm 10.9$ & 0.911 & $5.8 \pm 7.8$ & $6.0 \pm 7.0$ & 0.933 \\
\hline Ch_LL $\left({ }^{\circ}\right)$ & $2.4 \pm 10.0$ & $1.7 \pm 10.9$ & 0.634 & $-1.0 \pm 12.4$ & $0.2 \pm 10.7$ & 0.682 & $5.4 \pm 8.7$ & $3.0 \pm 13.9$ & 0.558 \\
\hline Ch_SS $\left({ }^{\circ}\right)$ & $-0.1 \pm 6.8$ & $-1.4 \pm 7.7$ & 0.164 & $-0.8 \pm 7.7$ & $-0.7 \pm 8.2$ & 0.965 & $1.6 \pm 6.0$ & $-0.3 \pm 8.3$ & 0.431 \\
\hline Ch_pelvic tilt $\left({ }^{\circ}\right)$ & $0.3 \pm 6.1$ & $0.6 \pm 5.6$ & 0.648 & $2.3 \pm 5.7$ & $1.4 \pm 4.7$ & 0.487 & $-2.1 \pm 7.1$ & $-0.5 \pm 5.3$ & 0.445 \\
\hline Ch_C7-S1 SVA (mm) & $-12.5 \pm 30.8$ & $-7.7 \pm 35.2$ & 0.245 & $-3.3 \pm 32.6$ & $-7.5 \pm 38.9$ & 0.672 & $-23.1 \pm 26.9$ & $-17.5 \pm 38.0$ & 0.618 \\
\hline
\end{tabular}

$\mathrm{Ch}_{-}=$changes of variables between pre- and postoperative period.

Data are reported as the mean \pm SD. Negative value indicates that the values measured in the postoperative period are lower than those measured in the preoperative period. 

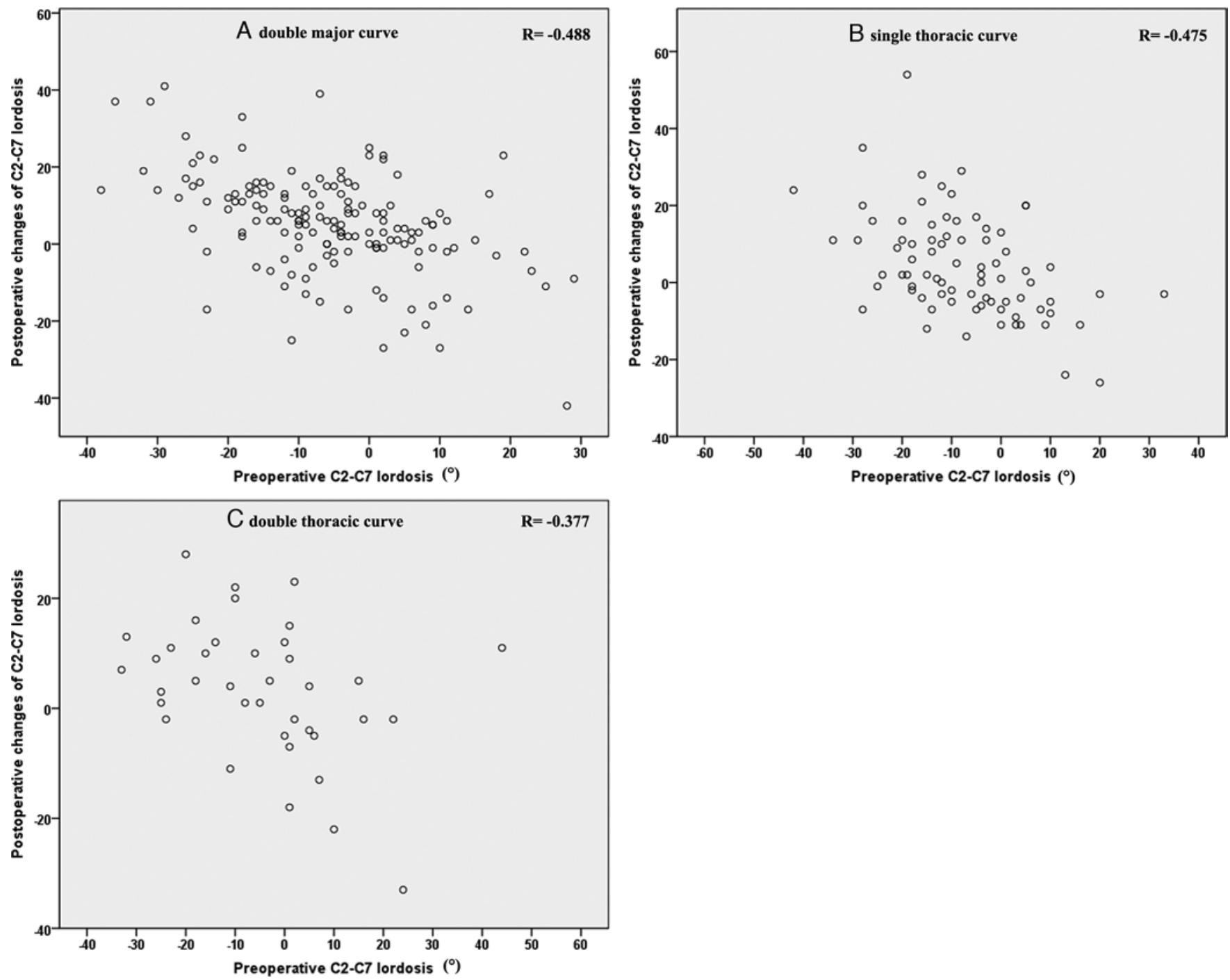

FIG. 4. Scatter plots showing the correlation between postoperative changes in C2-7 lordosis and preoperative C2-7 lordosis. A: Double major curve. B: Single thoracic curve. C: Double thoracic curve.

that the apex of TK is important for the position of cervical sagittal balance. ${ }^{9}$ Third, it was impossible to analyze the effect of the surgical technique because only the posterior derotational maneuver by pedicle screw fixation was used.
Hybrid techniques with hooks or anterior correction could lead to different results.

However, our study is meaningful because, to our knowledge, it is the first study to compare postoperative

TABLE 7. Pre- and postoperative comparisons of SRS-22 scores by CSA

\begin{tabular}{|c|c|c|c|c|c|c|}
\hline \multirow{2}{*}{$\begin{array}{l}\text { SRS-22 } \\
\text { Domain }\end{array}$} & \multicolumn{3}{|c|}{ Preop Score } & \multicolumn{3}{|c|}{ Final FU Score } \\
\hline & Cervical Lordosis $(n=105)$ & Cervical Kyphosis $(n=213)$ & $p$ Value & Cervical Lordosis $(n=145)$ & Cervical Kyphosis $(n=173)$ & $\mathrm{p}$ Value \\
\hline Function & $2.78 \pm 0.58$ & $2.67 \pm 0.49$ & 0.209 & $2.14 \pm 0.45$ & $2.26 \pm 0.45$ & 0.186 \\
\hline Pain & $3.33 \pm 0.36$ & $3.29 \pm 0.43$ & 0.612 & $3.00 \pm 0.33$ & $3.00 \pm 0.32$ & 0.904 \\
\hline Self-image & $2.07 \pm 0.47$ & $2.08 \pm 0.35$ & 0.911 & $2.03 \pm 0.27$ & $2.12 \pm 0.30$ & 0.107 \\
\hline Mental health & $2.57 \pm 0.42$ & $2.49 \pm 0.37$ & 0.209 & $2.22 \pm 0.42$ & $2.18 \pm 0.32$ & 0.526 \\
\hline Subtotal & $2.69 \pm 0.30$ & $2.63 \pm 0.23$ & 0.191 & $2.35 \pm 0.24$ & $2.39 \pm 0.20$ & 0.329 \\
\hline Satisfaction & $2.00 \pm 0.78$ & $2.17 \pm 0.79$ & 0.578 & $1.71 \pm 0.78$ & $1.76 \pm 0.64$ & 0.724 \\
\hline Total & $2.66 \pm 0.29$ & $2.61 \pm 0.23$ & 0.195 & $2.29 \pm 0.25$ & $2.33 \pm 0.20$ & 0.349 \\
\hline
\end{tabular}

Data are reported as the mean \pm SD. 
TABLE 8. Preoperative radiological risk factors for progression of cervical kyphosis

\begin{tabular}{|c|c|c|c|c|}
\hline Radiological Parameter & Restoration of $\mathrm{CL}(\mathrm{n}=205)$ & Aggravation of $C L(n=106)$ & p Value (univariate) & $\mathrm{p}$ Value (multivariate) \\
\hline UT curve angle $\left({ }^{\circ}\right)$ & $26.2 \pm 10.8$ & $26.0 \pm 12.5$ & 0.887 & NE \\
\hline MT curve angle $\left(^{\circ}\right)$ & $52.0 \pm 12.7$ & $50.9 \pm 12.6$ & 0.498 & NE \\
\hline TL/L curve angle $\left({ }^{\circ}\right)$ & $36.2 \pm 14.2$ & $35.3 \pm 13.8$ & 0.574 & NE \\
\hline Trunk shift $(\mathrm{mm})^{*}$ & $-1.3 \pm 15.1$ & $-1.7 \pm 15.4$ & 0.805 & NE \\
\hline T-1 tilt $\left({ }^{\circ}\right) \dagger$ & $-1.4 \pm 7.7$ & $-0.8 \pm 9.1$ & 0.553 & NE \\
\hline $\mathrm{C} 0-2 \mathrm{CL}\left({ }^{\circ}\right)$ & $27.2 \pm 8.5$ & $27.3 \pm 8.9$ & 0.944 & NE \\
\hline C2-7 CL $\left({ }^{\circ}\right) \ddagger$ & $-9.0 \pm 12.1$ & $0.7 \pm 13.1$ & $<0.001$ & $<0.001$ \\
\hline C2-7 SVA (mm) & $23.9 \pm 8.6$ & $24.8 \pm 9.5$ & 0.435 & NE \\
\hline T-1 slope $\left(^{\circ}\right)$ & $12.3 \pm 8.2$ & $15.7 \pm 9.1$ & 0.001 & 0.696 \\
\hline $\operatorname{TK}\left({ }^{\circ}\right)$ & $22.8 \pm 11.4$ & $25.9 \pm 12.8$ & 0.031 & 0.544 \\
\hline $\operatorname{LL}\left({ }^{\circ}\right)$ & $43.5 \pm 11.4$ & $25.9 \pm 12.8$ & 0.204 & NE \\
\hline $\operatorname{SS}\left({ }^{\circ}\right)$ & $37.6 \pm 9.1$ & $34.8 \pm 11.8$ & 0.039 & 0.372 \\
\hline Pelvic tilt $\left(^{\circ}\right)$ & $10.0 \pm 7.3$ & $12.2 \pm 7.4$ & 0.012 & 0.019 \\
\hline C7-S1 SVA (mm) & $1.3 \pm 28.0$ & $2.3 \pm 25.7$ & 0.780 & NE \\
\hline
\end{tabular}

$\mathrm{NE}=$ not entered; $\mathrm{UT}=$ upper thoracic.

Data are reported as the mean \pm SD.

* Negative value indicates that the C-7 plumb line is located on the left side of center of sacrum.

$\dagger$ Negative value indicates that the left side is more depressed than the right side.

$\ddagger$ Negative value indicates that the curve is kyphotic.

changes in CSA based on different curve types as well as preoperative cervical sagittal balance. Furthermore, another strength of our study is the relatively large number of patients.

\section{Conclusions}

Many patients (54.4\%) still showed cervical kyphotic alignment postoperatively regardless of the trend of improvement in CSA. C2-7 lordosis and C2-7 SVA improved postoperatively in all curve types. However, postoperative changes in C2-7 lordosis showed different results according to preoperative CSA, which could be related to T-1 slope and TK. However, clinical outcomes showed no difference according to CSA in this study cohort. Preoperative greater $\mathrm{C} 2-7$ lordosis and PT curve were risk factors for postoperative aggravation of CSA $(\mathrm{p}<0.001$ and $\mathrm{p}=$ 0.019 , respectively).

TABLE 9. Interobserver and intraobserver reliability of each radiological parameter

\begin{tabular}{ccc}
\hline Radiological Parameter & Interobserver & Intraobserver \\
\hline C0-2 CL & 0.840 & 0.972 \\
\hline C2-7 CL & 0.924 & 0.775 \\
\hline C2-7 SVA & 0.973 & 0.989 \\
\hline T-1 slope & 0.927 & 0.894 \\
\hline TK & 0.932 & 0.940 \\
\hline LL & 0.909 & 0.961 \\
\hline SS & 0.902 & 0.926 \\
\hline Pelvic tilt & 0.919 & 0.922 \\
\hline C7-S1 SVA & 0.986 & 0.975 \\
\hline
\end{tabular}

Data are reported as the ICC.

\section{Acknowledgments}

We thank Mi Young Lee, Sungjoo Cheon, So Jung Yoon, and A. Lyoun Lee for their contributions of data collection.

\section{References}

1. Canavese F, Turcot K, De Rosa V, de Coulon G, Kaelin A: Cervical spine sagittal alignment variations following posterior spinal fusion and instrumentation for adolescent idiopathic scoliosis. Eur Spine J 20:1141-1148, 2011

2. Charles YP, Sfeir G, Matter-Parrat V, Sauleau EA, Steib JP: Cervical sagittal alignment in idiopathic scoliosis treated by posterior instrumentation and in situ bending. Spine (Phila Pa 1976) 40:E419-E427, 2015

3. Glassman SD, Berven S, Bridwell K, Horton W, Dimar JR: Correlation of radiographic parameters and clinical symptoms in adult scoliosis. Spine (Phila Pa 1976) 30:682-688, 2005

4. Hikata T, Watanabe K, Fujita N, Iwanami A, Hosogane N, Ishii $\mathrm{K}$, et al: Impact of sagittal spinopelvic alignment on clinical outcomes after decompression surgery for lumbar spinal canal stenosis without coronal imbalance. J Neurosurg Spine 23:451-458, 2015

5. Hilibrand AS, Tannenbaum DA, Graziano GP, Loder RT, Hensinger RN: The sagittal alignment of the cervical spine in adolescent idiopathic scoliosis. J Pediatr Orthop 15:627632,1995

6. Hiyama A, Sakai D, Watanabe M, Katoh H, Sato M, Mochida J: Sagittal alignment of the cervical spine in adolescent idiopathic scoliosis: a comparative study of 42 adolescents with idiopathic scoliosis and 24 normal adolescents. Eur Spine J 25:3226-3233, 2016

7. Hwang SW, Samdani AF, Tantorski M, Cahill P, Nydick J, Fine A, et al: Cervical sagittal plane decompensation after surgery for adolescent idiopathic scoliosis: an effect imparted by postoperative thoracic hypokyphosis. J Neurosurg Spine 15:491-496, 2011

8. Ilharreborde B, Vidal C, Skalli W, Mazda K: Sagittal alignment of the cervical spine in adolescent idiopathic scoliosis 
treated by posteromedial translation. Eur Spine J 22:330 337,2013

9. Ito K, Imagama S, Ito Z, Ando K, Kobayashi K, Hida T, et al: Analysis of cervical kyphosis and spinal balance in young idiopathic scoliosis patients classified by the apex of thoracic kyphosis. Eur Spine J 25:3220-3225, 2016

10. La Maida GA, Zottarelli L, Mineo GV, Misaggi B: Sagittal balance in adolescent idiopathic scoliosis: radiographic study of spino-pelvic compensation after surgery. Eur Spine J 22 (Suppl 6):S859-S867, 2013

11. Lawton JO, Dickson RA: The experimental basis of idiopathic scoliosis. Clin Orthop Relat Res (210):9-17, 1986

12. Le Huec JC, Faundez A, Dominguez D, Hoffmeyer P, Aunoble S: Evidence showing the relationship between sagittal balance and clinical outcomes in surgical treatment of degenerative spinal diseases: a literature review. Int Orthop 39:87-95, 2015

13. Lee SH, Son ES, Seo EM, Suk KS, Kim KT: Factors determining cervical spine sagittal balance in asymptomatic adults: correlation with spinopelvic balance and thoracic inlet alignment. Spine J 15:705-712, 2015

14. Legarreta CA, Barrios C, Rositto GE, Reviriego JM, Maruenda JI, Escalada MN, et al: Cervical and thoracic sagittal misalignment after surgery for adolescent idiopathic scoliosis: a comparative study of all pedicle screws versus hybrid instrumentation. Spine (Phila Pa 1976) 39:1330-1337, 2014

15. Lenke LG, Edwards CC II, Bridwell KH: The Lenke classification of adolescent idiopathic scoliosis: how it organizes curve patterns as a template to perform selective fusions of the spine. Spine (Phila Pa 1976) 28:S199-S207, 2003

16. Matsumoto T, Kitahara H, Minami S, Takahashi K, Yamagata M, Moriya H, et al: Flexibility in the scoliotic spine: threedimensional analysis. J Spinal Disord 10:125-131, 1997

17. Pesenti S, Blondel B, Peltier E, Choufani E, Bollini G, Jouve JL: Interest of T1 parameters for sagittal alignment evaluation of adolescent idiopathic scoliosis patients. Eur Spine J 25:424-429, 2016

18. Roussouly P, Labelle H, Rouissi J, Bodin A: Pre- and postoperative sagittal balance in idiopathic scoliosis: a comparison over the ages of two cohorts of 132 adolescents and 52 adults. Eur Spine J 22 (Suppl 2):S203-S215, 2013

19. Tang JA, Scheer JK, Smith JS, Deviren V, Bess S, Hart RA, et al: The impact of standing regional cervical sagittal alignment on outcomes in posterior cervical fusion surgery. Neurosurgery 76 (Suppl 1):S14-21, 2015
20. Wang F, Zhou XY, Xu XM, Yang YL, Zhu XD, Bai YS, et al: Cervical sagittal alignment limited adjustment after selective posterior thoracolumbar/lumbar curve correction in patients with Lenke Type 5C adolescent idiopathic scoliosis. Spine (Phila Pa 1976) 42:E539-E546, 2017

21. Wang L, Liu X: Cervical sagittal alignment in adolescent idiopathic scoliosis patients (Lenke type 1-6). J Orthop Sci 22:254-259, 2017

22. Yanik HS, Ketenci IE, Erdem S: Cervical sagittal alignment in extensive fusions for Lenke $3 \mathrm{C}$ and $6 \mathrm{C}$ scoliosis: the effect of upper instrumented vertebra. Spine (Phila Pa 1976) 42:E355-E362, 2017

23. Youn MS, Shin JK, Goh TS, Kang SS, Jeon WK, Lee JS: Relationship between cervical sagittal alignment and healthrelated quality of life in adolescent idiopathic scoliosis. Eur Spine J 25:3114-3119, 2016

24. Yu M, Silvestre C, Mouton T, Rachkidi R, Zeng L, Roussouly P: Analysis of the cervical spine sagittal alignment in young idiopathic scoliosis: a morphological classification of 120 cases. Eur Spine J 22:2372-2381, 2013

\section{Disclosures}

The authors report no conflict of interest concerning the materials or methods used in this study or the findings specified in this paper.

\section{Author Contributions}

Conception and design: Cho. Acquisition of data: Choi. Analysis and interpretation of data: Cho, Hwang, Choi, DH Lee. Drafting the article: Cho. Critically revising the article: Hwang, CS Lee. Reviewed submitted version of manuscript: Hwang, Choi, DH Lee, CS Lee. Approved the final version of the manuscript on behalf of all authors: Cho. Statistical analysis: DH Lee. Administrative/technical/material support: Hwang. Study supervision: Hwang, DH Lee, CS Lee.

\section{Correspondence}

Jae Hwan Cho, Department of Orthopedic Surgery, Asan Medical Center, University of Ulsan College of Medicine, 388-1, PungNap2-dong, SongPa-gu, Seoul, Korea. email: spinecjh@gmail.com. 